\title{
Exercise Habits of Women 40 Ages and Over
}

\author{
Assoc. Prof. Dr. Fatma Çelik Kayapinar
}

Mehmet Akif Ersoy University, Physical Education, Burdur

\section{Doi:10.5901/mjss.2015.v6n2s5p163}

\begin{abstract}
The purpose of the research was to determine of habits about exercise of women of 40 ages and over. Research; December 2013 was made in Antalya province in Turkey. The research sample was consisted of 500 women. The data was taken into consideration; age, height, weight, marital status, number of children, education level, income level, active working life, health problems, treated diseases, hereditary diseases, operational status, prosthetic status in the body, psychological treatment or support, regular exercise habits and physical education lesson consisted questions. In the pre-implementation; The purpose of the research was explained and took verbal consent of the volunteer women. Frequency and percentages used for evaluation of the data. In conclusion; women were not have exercise habits and its reason that they were housewife.
\end{abstract}

Keywords: 40 ages and over, women, exercise, habit

\section{Introduction}

The development of technology has led so many daily physical task to do with a good deal of tools. And this resulted in to gain time for spare time spare time activities. Nevertheless so many people prefer to live immobile. Although human body designed to move and make challenging physical activities; yet the exercise is not among the daily efforts of average life style. (1)

It is stated that when human body lives without movements that its needs for a long time it will lose some of its functional capabilities; and these functional capabilities will cause so many diseases.

The diseases are defined as hypokinetic diseases in the end of sedentary life. (1)

The people who do not make regular exercise have very high risk to contract diseases such as coronary heart disease, high blood pressure, high cholesterol, cancer, musculoskeletal disorders and obesity. $(1,2)$

According to the health risks the most effective types of exercise are such increasing aerobic capacity as walking, jogging, hiking, biking, boating, and swimming. With aerobic exercises high efficiency could obtain to eliminate such diseases which are particularly obesity, cardiovascular disease and deformation of the bones. (3)

Many studies shows that active individuals have lower risk to have heart disease than sedentary people. Recent studies emphasizes that the regular exercises and level of cardiorespiratory fitness are very important to prevention of heart diseases. (4-5)

In the period of middle ages and above physical suitability levels are decreases and thus increases the risk of diseases. The serious diseases which are more frequently observed in this period as heart disease, osteoporosis, obesity, hypertension, cancer and diabetes threatens society as effects adversely individuals.

Obesity is a major risk factor for coronary heart disease. Obesity is characterized by the height of the excess fat and endomorphy rate and inactive, sedentary lifestyle is one of the causes of obesity $(6,7)$.

This study 40 years and older was conducted to investigate the level of knowledge about exercise in women.

\section{Materials and Methods}

The research sample was consisted of 500 women. Research method is screening model. Percent and frequency are used to evaluating the data. The data taken into consideration; age, height, weight, marital status, number of children, education level, income level, working life, health problems, treatment finished diseases, hereditary diseases, an operation status, prosthetic status in the body, psychological treatment support, regular exercise habits and physical education consists of questions about the course. December 2013 on the application was made in Antalya province.

Survey prior to application; aim is then discussed and made verbal consent of the volunteer women. 


\section{Results and Interpretation}

Table 1: Percent and Frequency Results.

\begin{tabular}{|l|c|c|c|c|}
\hline Variable & Answer & $\%$ & $\mathrm{n}$ & Total \\
\hline Marital Status & Married & $\% 76,4$ & 382 & 500 \\
\hline Do You Work? & No & $\% 66,6$ & 333 & 500 \\
\hline Did You Have Working Life? & Never Worked & $\% 61,4$ & 307 & 500 \\
\hline Do You Have Health Problems? & Yes & $\% 50,6$ & 253 & 500 \\
\hline Do You Have Finished Your Treatment Discomfort? & NO & $\% 79,6$ & 398 & 500 \\
\hline Do You Have Any Hereditary Disease? & No & $\% 79,4$ & 397 & 500 \\
\hline Have You Had Surgery? & Yes & $\% 58,4$ & 292 & 500 \\
\hline Is There A Prosthesis? & No & $\% 80,2$ & 401 & 500 \\
\hline Do You Have Any Psychological Treatment? & No & $\% 80,4$ & 402 & 500 \\
\hline Do You Take Regular Exercise? & No & $\% 57,0$ & 285 & 500 \\
\hline Is Your Exercise Affects Your State Income? & No & $\% 74,4$ & 372 & 500 \\
\hline \multirow{2}{*}{ What Are The Factors That Affect Your Exercising? } & I'm Not Interested & $\% 6,3$ & 23 & \multirow{2}{*}{500} \\
\cline { 2 - 4 } & Losing Weight & $\% 4,9$ & 18 & \\
\hline Do You Think That Regular Exercise Has An Effect On Health? & Yes & $\% 95,6$ & 478 & 500 \\
\hline How Many Years Have You Taken Physical Education Classes? & 11 Year & $\% 25$ & 125 & 500 \\
\hline Have You Exercise A Directed In Physical Education Classes? & No & $\% 49,8$ & 249 & 500 \\
\hline
\end{tabular}

Research group; 48.8 years of age, height $156.8 \mathrm{~cm}, 69.1 \mathrm{~kg}$ of body weight ratio was composed of 500 women with an average volunteer.

According to the lady of the data obtained; response options being married the marital status was determined that $30.8 \%$ of high school education $76.4 \%$ status.

How much is the monthly income? The question; the answer is not the income you $48.2 \%$ Work? "No answer to the question $66.6 \%$ of the active working life by how many years? 'question was found to give 61.4 reputation no response.

Do you have health problems? Received $50.6 \%$ answered yes to the question; What was that about health problems from blood pressure responses received, 10\%, 4.5\% glucose, thyroid, 3.5\%, 3.5\% asthma, rheumatism, 2.5\%, $2.5 \%$ hernia, heart rate is $1.5 \%$ respectively.

Do you have finished your treatment discomfort? $79.6 \%$ of the question, no, $14.6 \%$ yes; If that is what the finished treatment of gynecological diseases and disorders response rate reached $17.5 \%$.

Do you have any hereditary disease? Questions to $79.4 \%$ no, $20.6 \%$ yes; $28.6 \%$ of what disturbed that hereditary blood pressure, $14.3 \%$ sugar, reached the value of $8.8 \%$ of heart failure.

Have you had surgery? $58.4 \%$ to the question, yes, $40.8 \%$ no; What are the answers that passed cesarean surgery $25.7 \%, 12.3 \%$, gynecological diseases, appendicitis, $5.7 \%, 5.4 \%$, gallbladder, breast $4.2 \%, 2.3 \%$ nose, goiter and $1.9 \%$ thyroid, and kidney hemorrhoid 1.5\% 1.1\% meniscus has been found that eyes and hernia surgery.

Is there a prosthesis? Questions to no $80.2 \%$ yes 19.8\%; where the response has been reached that the prosthesis in the mouth with $80.8 \%$.

Do you have any psychological treatment? Questions $80.4 \%$ no, $17.2 \%$ yes; Did you using psychological medicine or did you use? $55.1 \% 25.5 \%$ yes to the question, no answer was given over $19.4 \%$ yes, I'm still using.

Do you take regular exercise? Questions to $57.0 \%$ of the women with $41.8 \%$ yes no life without active exercise greatly; How many days per week do you do sports? 3 day $36.2 \%$ of the question, how many hours do you do? Questions to $67.5 \%$ for 1 hour, did you or do you do if exercise alone group 'to have reached $55.4 \%$ only answer. Does the doctor have been recommended by doctors and $51.3 \%$ of the questions that have no incentive to exercise and exercise affect your case for you to exercise your income? If the question has been no $74,4 \%$.

What are the factors that affect your exercising? Questions do not have time to $17.3 \%, 17.3 \%$ gave the answer to be healthy. $15.6 \%$ cannot because of my illness, feels lazy $12.9 \%, 6.3 \%$ I'm not interested, I'm due to weakening of $4.9 \%$, $4.4 \%$ has been reached, and I do to lose weight to be more healthy response.

Do you think that regular exercise has an effect on health? $95.6 \%$ yes to the question; explanation of $17.8 \%$ as the response is beneficial to health, health and quality of life was found to give the answer to $12.6 \%$. 
How many years have you taken physical education classes? 25\% Question 11 years, 5 years, 21.8\%, 9.2\% for 8 years, 12 years, $8.0 \%, 4.4 \%$ for 6 years and $4.0 \% 3$ years is found to be $2.2 \%$ for 15 years. Directed to exercise in physical education classes? Questions to $49.8 \%$ no, $41.4 \%$ yes, the physical education teacher or your teacher gave information about the benefits of exercise? If yes to Question $51.0 \%$ response rate was achieved in $38.0 \%$ no.

\section{Recommendations}

1. Women can exercise by municipalities for days that can be applied in every neighborhood.

2. Training on behalf of the lack of awareness by the experts to do the exercises, you can increase awareness by giving lectures and sayings.

3. Exercise to lose weight by making a measurement of days per month and ensuring that the tightening observed in the concrete can be increased participation in exercise.

4. Athletes during certain times of the day may be asked to exercise participation and bringing women athletes / athletes achieved to see visually.

5. By the State; units can be installed about to have a healthy weight.

6. Weight control, and institutions such as health centers can be done with patient follow-up.

7. Ministry of Education of physical education lessons and work done to create the habit of exercising their applications.

8. Exercise incentive for future weight gain experienced by the Ministry of Youth and Sports, on behalf of failure rate, projects to acquire the habit of doing exercise can be carried out.

\section{References}

Özer, K. (2001). Physical Fitness, 1st edition, Nobel Publications, Ankara

Peker, I., Çiloğlu, F., Buruk, Ş. (2000). Effects of Exercise and Exercise + Diet Blood Lipids, Sports Research Journal (2): 33-46.

Zorba, E. (1999). 1. Everyone's Sports and Physical Fitness, Meyir Printing, Ankara.

Howley ET, Franks BD. Health Fitness, Second Edition, Human Kinetics Publishers Ltd, Champaign, Illinois 1992

Solak H, Görmüş IS, Solak T, Görmüş N. Sports and our heart, Nobel Publications, Ankara 2002.

Carter JEL, Heath BH. Somatotyping-Development and Application, University Pres, Cambridge 1990.

Chisholm DJ, Samaras K, Markovic T, Carey D, Lapsys N, Campbell LV. Obesity: Genes, Glands or Gluttony?, Reprod Fertil Dev, 1998, 10(1): 49-538. 